\title{
A SUSTENTABILIDADE E A ACADEMIA
}

José Antônio Baptista Neto jabneto@id.uff.br Universidade Federal Fluminense UFF, Niterói, Rio de Janeiro, Brasil.

\section{Fabiana Cunha Leão} Pompermeyer

fabiana.educato@gmail.com Universidade Federal Fluminense UFF, Niterói, Rio de Janeiro, Brasil.

\section{Estefan Monteiro da Fonseca}

oceano25@hotmail.com Universidade Federal Fluminense UFF, Niterói, Rio de Janeiro, Brasil.
Original de Estocolmo, na Suécia, o conceito de sustentabilidade foi criado na Conferência das Nações Unidas sobre o Meio Ambiente Humano, realizada em 1972. Seus principios, porém, já tinham sido levantados no ano anterior, quando da publicação, em 1971, do documento "Os Limites do Crescimento". Essa publicação procurou gerar uma narrativa baseada na conciliação entre a economia e a preservação do meio ambiente. Assim, o conceito sustentabilidade tem como premissa o princípio básico do continuísmo, uma vez que nada pode ser sustentável se não for contínuo.

O desenvolvimento sustentável significa a evolução contínua e saudável, sustentada na capacidade do sistema socioeconômico de não perder energia, se fazendo disponível para gerações futuras. As principais limitações do conceito se relacionam à velocidade do desenvolvimento tecnológico e à capacidade de suporte dos estoques naturais. Essas limitações foram se acentuando em progressão geométrica, uma vez que o ritmo do crescimento humano se deu e continua na mesma forma. Só nos últimos dois séculos, os avanços da população e da economia globais superaram qualquer número absoluto anterior (Alves, 2012). Outras fontes projetam um número médio populacional de 11 bilhões de pessoas para o ano de 2100 (United Nations, 2015), o que fatalmente pode resultar em escassez de recursos naturais e consequentes crises nos processos de produção e gestão das sociedades.

Dentro deste contexto, a ciência, cujo protagonismo pertence a academia, assume um papel fundamental: o questionamento constante do modus operandi em todos os estágios da indústria e gestão pública. Assim, a academia não pode se eximir da responsabilidade da quebra de paradigmas e da geração de inovação, já que ambas estão intrisicamente ligadas. A pressão das atividades humanas sobre o equilíbrio natural tem estimulado a comunidade científica a desenvolver técnicas de produção e reaproveitamento baseados no novo conceito de economia circular. Este conceito se baseia na ciclagem de recursos e economia de energia, potencializando a produção e resultando em menos impactos em termos de gasto de energia e geração de resíduos. A economia circular também se sustenta na logística reversa, que configura-se como um conjunto de procedimentos que visam à coleta e devolução dos resíduos sólidos ao setor produtivo, o que equivale às etapas de remanufatura e reciclagem na economia circular.

Assim, a sustentabilidade aparece como um polinômio cujos inúmeros parâmetros interferentes devem ser identificados e inseridos na equação. Eficiência é o conceito que serve de pano de fundo para a sustentabilidade, estando ligada inclusive com a inteligência de transporte, exemplificada no presente número da revista S\&G como "Food Miles". O conceito de milhas alimentares, originário do Reino Unido, tem sido usado para sugerir que importar alimentos de países distantes representa inerentemente mais desperdício do que cultivar e consumir produtos locais (Kemp et al., 2010). Aspectos como otimização da pro- 
dução também são abordados nesta edição, e estão representados na carcinicultura e na utilização de métodos para o aumento de produção.

Por fim, a edição ainda aborda o uso da tecnologia como forma de estratégia para a tomada de decisões, o que representa um exemplo claro do uso de dados para a melhoria dos índices de efetividade na gestão mais eficiente e promoção da sustentabilidade. A gestão de estratégias direcionadas à sustentabilidade exige do líder a capacidade de conjugar múltiplos parâmetros e escalas de forma simultânea. Nesse sentido, as ferramentas tecnológicas surgem como um elemento catalizador da eficiência (Checkland, 2000).

\section{REFERÊNCIAS}

Checkland, P. (2000). Soft systems methodology: a thirty year retrospective. Systems Research and Behavioral Science, 17, 511-558. https://doi.org/10.1002/1099-1743(200011)17:1+<::AID-SRES374>3.0.CO;2-O

Alves, J. E. D. (2014). População, desenvolvimento e sustentabilidade: perspectivas para a CIPD pós-2014. Revista Brasileira de Estudos de População, 31, 219-230. https://doi. org/10.1590/S0102-30982014000100013

Kemp, K., Insch, A., Holdsworth, D. K., Knight, J. G. (2010). Food miles: Do UK consumers actually care? Food Policy, 35, 504-513. https://doi.org/10.1016/j.foodpol.2010.05.011.

United Nations. (2015). World Populations Prospects: World Population Prospects: The 2015 Revision, Key Findings and Advance Tables. Working Paper No. ESA/P/WP.241. https:// population.un.org/wpp/Publications/Files/Key_Findings_ WPP_2015.pdf 